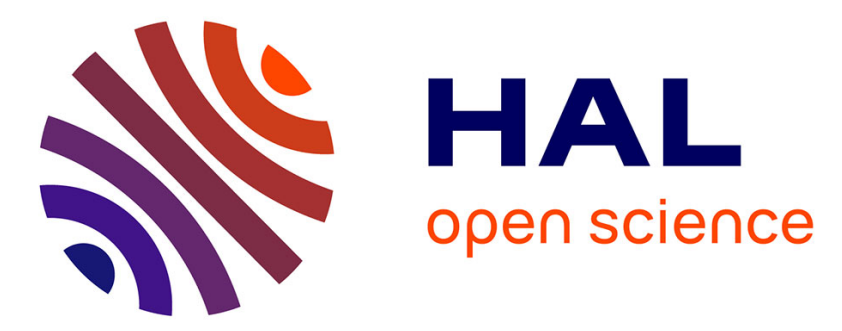

\title{
Low-molecular-weight color pI markers to monitor on-line the peptide focusing process in OFFGEL fractionation
}

Sylvie Michelland, Sandrine Bourgoin-Voillard, Valérie Cunin, Axel Tollance, Pascal Bertolino, Karel Slais, Michel Sève

\section{To cite this version:}

Sylvie Michelland, Sandrine Bourgoin-Voillard, Valérie Cunin, Axel Tollance, Pascal Bertolino, et al.. Low-molecular-weight color pI markers to monitor on-line the peptide focusing process in OFFGEL fractionation. Electrophoresis, 2017, 38 (16), pp.2034-2041. 10.1002/elps.201700075 . hal-01596279

\author{
HAL Id: hal-01596279 \\ https://hal.science/hal-01596279
}

Submitted on 1 Dec 2017

HAL is a multi-disciplinary open access archive for the deposit and dissemination of scientific research documents, whether they are published or not. The documents may come from teaching and research institutions in France or abroad, or from public or private research centers.
L'archive ouverte pluridisciplinaire HAL, est destinée au dépôt et à la diffusion de documents scientifiques de niveau recherche, publiés ou non, émanant des établissements d'enseignement et de recherche français ou étrangers, des laboratoires publics ou privés. 
A low-molecular-weight color pI markers to monitor on-line the peptide focusing process in OFFGEL fractionation

Sylvie Michelland ${ }^{1,2}$, Sandrine Bourgoin-Voillard ${ }^{1,2}$, Valérie Cunin ${ }^{1,2}$, Axel Tollance ${ }^{1,2}$, Pascal

Bertolino $^{3}$, Karel Slais ${ }^{4}$, Michel Seve ${ }^{1,2}$

1 Univ. Grenoble Alpes, Inserm, U1055, LBFA and BEeSy, PROMETHEE Proteomic Platform, Grenoble, France

2 CHU de Grenoble, Institut de Biologie et de Pathologie, PROMETHEE Proteomic Platform, Grenoble, France

3 Univ. Grenoble Alpes, GIPSA-lab, Grenoble, France

4 Institute of Analytical Chemistry of the Academy of Sciences of the Czech Republic, v.v.i., Brno, Czech Republic

Corresponding author: Dr Sylvie Michelland

CHU Grenoble alpes, Institut de Biologie et de Pathologie, PROMETHEE Proteomic Platform, Boulevard de la Chantourne, 38700 La tronche

Email: $\underline{\text { SMichelland@chu-grenoble.fr }}$

Fax: +33-4-76-76-87-93

\section{Keywords}

iTRAQ labeling/ low-molecular-weight color pI markers/ Peptides OFFGEL fractionation

Total number of words: 4533 


\begin{abstract}
High-throughput mass spectrometry-based proteomic analysis requires peptide fractionation to simplify complex biological samples and increase proteome coverage. OFFGEL fractionation technology became a common method to separate peptides or proteins using isoelectric focusing in an immobilized $\mathrm{pH}$ gradient. However, the OFFGEL focusing process may be further optimized and controlled in terms of separation time and pI resolution. Here, we evaluated OFFGEL technology to separate peptides from different samples in the presence of lowmolecular-weight (LMW) color pI markers to visualize the focusing process. LMW color pI markers covering a large $\mathrm{pH}$ range were added to the peptide mixture before OFFGEL fractionation using a 24-wells device encompassing the $\mathrm{pH}$ range 3-10. We also explored the impact of LMW color pI markers on peptide fractionation labeled previously for iTRAQ. Then, fractionated peptides were separated by RP_HPLC prior to MS analysis using MALDITOF/TOF mass spectrometry in MS and MS/MS modes. Here we report the performance of the peptide focusing process in the presence of LMW color pI markers as on-line trackers during the OFFGEL process and the possibility to use them as pI controls for peptide focusing. This method improves the workflow for peptide fractionation in a bottom-up proteomic approach with or without iTRAQ labeling.
\end{abstract}




\section{Introduction}

In bottom-up proteomic approaches, peptide fractionation is an extremely important step which reduces sample complexity and consequently improves the identification of low-abundance proteins by mass spectrometry. OFFGEL Electrophoresis (OGE) technology is well known as a robust tool to separate peptides and improve protein coverage [1]. For this purpose, OGE is an efficient separation technique for peptides from complex samples and is informative for $\mathrm{pI}$ peptides. Indeed during OGE, peptides migrate through the immobilized $\mathrm{pH}$ gradient (IPG) strip until they reach the $\mathrm{pH}$ corresponding to their $\mathrm{pI}$ at a specific well. Then, they can be easily recovered in solution for further analysis. This $\mathrm{pI}$ value can be used as supplementary validation criteria for peptide identification [2]. During the last decade, OGE was successfully combined with quantitative proteomic approaches such as iTRAQ labeling, to investigate biological systems [3-5] and particularly in the discovery of biomarkers. It was demonstrated that iTRAQ labeling was compatible with OGE for plasma and secretome samples [6], complex eukaryotic samples $[7,8]$ and plants extracts $[9,10]$. Although the iTRAQ tag induces a small pI shift of labeled peptides compared to unlabeled peptides, this difference was comparable to the error of pI calculation $[6,11]$. However, OGE remains a manual technique with several steps of handling and lacks standardization and validation criteria to ensure reproducible separations. In this context, we propose to greatly improve the quality of experiments by using novel stable pI markers, either alone or mixed, during OGE. These OGE pI markers are compatible with biological samples, a quantitative approach, OGE and mass spectrometry. In this work, we investigated OGE fractionation which is visually monitored by a mixture of low-molecular-weight (LMW) color pI markers. The chosen LMW color pI markers have to fulfill several criteria such as an appropriate repartition along the strip $\mathrm{pH} 3-10$, a high color intensity for different pI values, a good focusing, water solubility and stability during the focusing process $[12,13]$. Hence, we studied peptides OFFGEL fractionation of simple and 
complex samples in presence of this LMW color pI marker mixture. We also evaluated the compatibility to use this LMW color pI marker mixture as a control of the focusing for LCMS/MS experiments as well as for iTRAQ-LC-MS/MS experiments.

\section{Materials and Methods}

\subsection{LMW color $\mathrm{pI}$ markers and protein samples}

LM color pI markers were developed, prepared in K. Slais's laboratory mainly by diazotation and/or Mannich reaction [14-16] and adapted to OGE fractionation of peptides. The position of LMW color pI markers on an IPG strip was used to follow the separation process. We used a mixture of five LMW color pI markers with an appropriate repartition along the strip pH 3-10. For each LMW color pI markers, a stock solution was prepared at either $2 \mu \mathrm{g} / \mu \mathrm{L}$ or $10 \mu \mathrm{L} / \mu \mathrm{L}$ in ultrapure water (Sigma, Lyon, France). Then, LMW color pI markers were added to the OGE buffer at the following quantities: $100 \mu \mathrm{g}$ for dark orange, pI 3.9; yellow, pI 10.1; orange, pI 8.0 and $50 \mu \mathrm{g}$ for lavender, $\mathrm{pI} 5.3$; red, pI 6.3. The names of markers are reported in Table 1. Human Serum Albumin (HSA) from a lyophilized powder, $\geq 96 \%$, was purchased from SigmaAldrich. An MS-compatible Human Proteome (HP) sample was prepared as a whole-cell protein extract from human K562 cells (Promega, France) according to the supplier data. As the HP stock solution was solubilized in $6.5 \mathrm{M}$ urea/50 mM Tris- $\mathrm{HCl}(\mathrm{pH} 8)$ at a protein concentration of $10 \mathrm{mg} / \mathrm{mL}$, the solution was diluted 6.5 times in $0.5 \mathrm{M}$ of TEAB (Triethylammonium Bicarbonate) prior to reduction/ alkylation/digestion processes.

\subsection{Protein digestion and iTRAQ labeling}

HSA and HP were digested and half of the samples were labeled with iTRAQ reagents in a 4plex set according to the manufacturer's instructions (iTRAQ Reagents 4-plex Applications kit; Sciex, Foster City, Cal, U.S.A). Briefly, $400 \mu \mathrm{g}$ proteins from each sample were reduced in 20 $\mathrm{mM}$ of TCEP (tris(2-carboxyethyl)phosphine) at $37^{\circ} \mathrm{C}$ for $1 \mathrm{~h}$ and alkylated in $10 \mathrm{mM}$ of MMTS (methylmethane thiosulfonate) at RT for $10 \mathrm{~min}$, followed by trypsin (Promega) digestion in a 
ratio of 1:10 (trypsin: protein) overnight at $37^{\circ} \mathrm{C}$. Each peptide solution was labeled at $\mathrm{RT}$ for $1 \mathrm{~h}$ with one iTRAQ reagent vial previously reconstituted with $70 \mu \mathrm{L}$ of ethanol for 4 plex iTRAQ reagent. Then, the different labeled peptides were pooled in a single vial and dried by evaporation using a Speed-Vac. Samples digested but not labeled with iTRAQ were directly dried by evaporation.

\subsection{Peptide OFFGEL Isoelectrofocusing}

For pI-based peptide separation, we used the 3100 OFFGEL Fractionator with OFFGEL Kit linear $\mathrm{pH}$ 3-10 (Agilent Technologies) in a 24-well setup following the manufacturer's instructions. Peptides (from $100 \mu \mathrm{g}$ to $400 \mu \mathrm{g}$ ) were suspended with $3.6 \mathrm{~mL}$ of focusing OFFGEL buffer in presence or /not of LMW color pI marker mix $(120 \mu \mathrm{L})$. Then after rehydration of the 24-cm IPG gel strip (GE Healthcare, Germany), $150 \mu \mathrm{L}$ of sample was loaded in each well. Peptides electrofocusing was performed at $20^{\circ} \mathrm{C}$ and $50 \mu \mathrm{A}$ until $50 \mathrm{kVh}$ was reached. After fractionation was completed, each fraction was transferred in individual tubes. Then, the wells were washed with $150 \mu \mathrm{L}$ of a solution of water/methanol (50:50). After $15 \mathrm{~min}$, each corresponding peptide fraction was pooled, concentrated by vacuum centrifugation and desalted using C18 ZipTips (Millipore, MA, USA). The desalted samples were collected, dried using a vacuum concentrator prior to nanoLC-MS/MS analysis and direct MS/MS analysis.

\subsection{Reversed Phase Nanoliquid Chromatography}

Fractions obtained by OGE fractionation of HP samples were further fractionated by using an Ultimate 3000 C18 reversed-phase liquid chromatography system controled by Chromeleon v. 6.80 software (Dionex/ThermoScientific/LC Packings, Amsterdam, The Netherlands) and coupled to a Probot MALDI spotting device controled by the $\mu$ Carrier 2.0 software (Dionex/Thermo Scientific/LC Packings, Amsterdam, The Netherlands). For this step, each OGE fraction was re-dissolved in $10 \mu \mathrm{L}$ buffer A (98\% water, $2 \% \mathrm{ACN}$ and $0.05 \%$ TFA). Peptides

were trapped on a C18 trapping column (C18, $3 \mu \mathrm{m}, 100 \AA$ pore size; LC Packings $)$ for 5 min 
using buffer A at a flow rate of $20 \mu \mathrm{L} / \mathrm{min}$, and then separated for $60 \mathrm{~min}$ by $\mathrm{C} 18$-reversed phase chromatography (Acclaim PepMap100 $75 \mu \mathrm{m}$ id x $15 \mathrm{~cm}$, nano-Viper C18, $3 \mu \mathrm{m}, 100 \AA$ Å pore size; Thermo Scientific) with a binary gradient of buffer A (2\% ACN and $0.05 \%$ TFA) and buffer $\mathrm{B}(80 \% \mathrm{ACN}$ and $0.04 \% \mathrm{TFA})$ at a flow rate of $0.3 \mu \mathrm{L} / \mathrm{min}$. The nanoLC gradient was set up as follows: 5-35 $\min , 8-42 \% \mathrm{~B}$; 35-40 $\min , 42-58 \% \mathrm{~B}$; 40-50 $\mathrm{min}, 58-90 \% \mathrm{~B}$ and 50-60 min, $100 \%$ A. Column effluents were mixed in a ratio of 1:3 with MALDI matrix (HCCA, $2 \mathrm{mg} / \mathrm{mL}$ in $70 \% \mathrm{ACN}$ and $0.1 \%$ TFA). They were collected for $15 \mathrm{~s}$ and spotted on an Opti-tof LC/MALDI Insert 123 x $81 \mathrm{~mm}$ plate (Sciex, Les Ulis, France) to produce 200 spots per OGE fraction.

\subsection{MALDI TOF/TOF analysis}

MS and MS/MS analyses were performed using the 4800 MALDI-TOF/TOF mass spectrometer (Sciex, Les Ulis, France) controled by the 4000 Series Explorer software v. 3.5. For LMW color pI marker analysis, MS spectra were acquired in positive reflector ion mode in an $\mathrm{m} / \mathrm{z}$, range of 250-650. MS/MS spectra were performed manually for each LMW color pI marker ion by using collision-induced dissociation (CID) as the activation mode. For peptide analysis, MS spectra were acquired in positive reflector ion mode in an $\mathrm{m} / \mathrm{z}$ range of $700-4000$. The 30 most intense ion signals per spot position having an $\mathrm{S} / \mathrm{N}>20$ were selected as precursor ions for MS/MS analysis. MS/MS analyses were performed automatically byusing CID as the activation mode.

\subsection{Data analysis}

Characterization of LMW color pI markers was performed by analyzing MS and MS/MS spectra with Data explorer V 4.9 software (Sciex). For protein analysis, MS and MS/MS spectra were used for identification and relative quantification by using ProteinPilot software v 4.5 with Mascot or Paragon search engines (Sciex, Les Ulis, France). A bioinformatic analysis was made for Homo sapiens species in the Uniprot/swissprot database (downloaded January 2016) using the search parameters of cysteine alkylation (MMTS) andtrypsin cleavage specificity. For the 
quantitation analysis we added parameters of iTRAQ 4-plex peptide label and processed with a thorough ID and the False Discovery Rate Analysis (FDR) of 1\%. We calculated the pI of peptides identified with a confidence level higher than $95 \%$ in all samples by using the $\mathrm{pI} / \mathrm{Mw}$ tool of the ExPASy Proteomic Server (www.expasy.org). It should be noted that deamidation of $\mathrm{N}$ and $\mathrm{Q}$ residues induces a non-negligible $\mathrm{pI}$ shift since $\mathrm{N}$ and $\mathrm{Q}$ amino acids become $\mathrm{D}$ and $\mathrm{E}$ amino acids, respectively. Thus, using our custom bioinformatics software ("Deamidated"), we replaced the deamidated $\mathrm{N}$ and $\mathrm{Q}$ residues with $\mathrm{D}$ and $\mathrm{E}$ residues respectively, in the sequence of peptides prior to $\mathrm{pI}$ calculation with the $\mathrm{pI} / \mathrm{Mw}$ tool of the ExPASy Proteomic Server (www.expasy.org).

\section{Results and discussion}

OGE electrofocusing is known as a powerful method for an efficient and reproducible separation of peptides and proteins $[2,17]$. Unlike the peptide $\mathrm{pI}$ markers used to determine the $\mathrm{pI}$ values of peptides and proteins [18], the mixture of LMW color pI markers that we report may be useful for direct observation of peptide/ protein focusing without interfering with peptide/ protein identification. We also explored the impact of LMW color pI markers in the context of a quantitative proteomic approach based on ITRAQ coupled with OGE peptide fractionation.

\subsection{OGE electrofocusing for LMW color pI markers}

OGE electrofocusing was performed in 24 wells using a strip covering the $\mathrm{pH}$ of 3 to 10 with 3/10 carrier ampholytes in order to create the $\mathrm{pH}$ gradient. OGE electrofocusing was processed with the five individual LMW color pI markers together (mixture) or with each LMW color pI marker individually. A similar OGE focusing was observed for both conditions. . The list of LMW color pI markers used in this work and their characteristics were reported in Table 1. For both individual $\mathrm{pI}$ marker focusing and mixture focusing of the five pI markers, each LMW color pI marker focalized at the same position along the strip for OGE. We observed dark orange (marker I, pI 3.9) at fraction 1, lavender (marker II, pI 5.3) at fraction 9, red (marker III, pI 6.2) 
at fraction 13, yellow (marker IV, pI 7.2) at fraction 17 and orange (marker V, pI 8.0) at fraction 20. Expected $\mathrm{pH}$ ranges by fraction were calculated according to the IPG strip supplier data and the OGE fraction size, as reported in our previous study [6]. For all pI markers, we observed a slight difference between theoretical focusing fractions and experimental focusing fractions. This difference was $\pm 0.3 \mathrm{pH}$ units for four of the five $\mathrm{pI}$ markers, which is a shift that is within the expected variability of OGE technique [17]. Thus, regarding the focusing observed for the mixture of the five $\mathrm{pI}$ markers and individual $\mathrm{pI}$ markers, OGE seems a suitable technique to focalize efficiently the mixture of LMW color pI markers (I, II, III, IV and V) as well as individual LMW color pI markers.

\subsection{Mass spectrometry characterization of LMW color pI markers}

Since the LMW color pI markers used in this study were never characterized by mass spectrometry, we used a MALDI-TOF/TOF mass spectrometer operating in a positive reflector mode to establish both MS and MS/MS spectra of each LMW color pI marker (Fig. 1). MS spectra showed ions of the HCCA matrix $(\mathrm{m} / \mathrm{z} 306.1644, \mathrm{~m} / \mathrm{z} 330.1158, \mathrm{~m} / \mathrm{z}, 379.0818, \mathrm{~m} / \mathrm{z}$ 416.1640 and $m / z, 463.2935)$ and the molecular ion $[\mathrm{M}+\mathrm{H}]^{+}$of each individual LMW color pI marker which matches with their expected $m / z$ values. MS spectra of LMW color pI markers I, II, III, IV and V yielded ions at $m / z$ 271.0900, 623.0820, 581.1700, 253.1193 and 404.1405 corresponding to their molecular ion $[\mathrm{M}+\mathrm{H}]^{+}$, respectively. Although several ions was observed in the MS spectrum of marker $\mathrm{V}$, the base peak was observed at $\mathrm{m} / \mathrm{z} 404.1405$ corresponding to the molecular ion of marker $\mathrm{V}[\mathrm{Mv}+\mathrm{H}]^{+}$. All MS/MS spectra showed product ions with high abundance with a different fingerprint for each LMW color pI marker, which suggested that they may be useful for marker identification. In addition to precursor ions, a loss of $87 \mathrm{u}\left(\mathrm{C}_{4} \mathrm{H}_{9} \mathrm{NO}\right)$ was observed in MS/MS analysis for markers II, III, IV and V. For pI marker I, we observed a loss of $\mathrm{H}_{2} \mathrm{O}$ and a loss of $\mathrm{CO}_{2}$. Moreover, the low $m / z$ range of precursor ions from $m / z 250$ to $m / z 700$ limited any interference from peptides in the MS analysis since the MS spectra of 
peptides were recorded within the mass range of 700-3500 $\mathrm{m} / \mathrm{z}$. Other different LMW color pI markers were previously used [19] for the successful determination of protein pI values in gel electrofocusing (not including OGE) and mass spectrometry analysis, especially in complex mixtures. But,theirmass spectra were more complex in terms of number of peaks and required a dual mass spectrometry analysis in positive and negative ion modes. In contrast, our color LMW color pI markers showed specific and simple MS and MS/MS mass spectra, which allowed an unambiguous characterization in positive mode.

\subsection{Identification of HSA with or without low molecular weight color pI marker}

The HSA digest was fractionated using OGE in presence or absence of the LMW color pI marker mixture before C18 desalting and mass spectrometry analysis. In combination with HSA protein, we observed a good focusing of LMW color pI markers along the strip on fractions 1, 9, 13, 17 and 20 in good agreement with OGE experiments for LMW color pI markers without protein (part 3.1). Then, HSA peptides were identified in all fractions in presence or absence of the LMW color pI marker mixture (Fig. 2). Although the number of peptides identified in all 24 fractions was slightly lower (143 vs 153) in the presence of LMW color pI markers, the number of peptides identified in each fraction remained similar whether or not LMW color pI markers were used (Fig. 2A). Furthermore, LMW color pI markers had no effect on HSA identification. HSA was identified in all fractions in both experiments with a coverage from $6 \%$ (fractions with not many peptides e.g. fractions 7,14 ) to $22 \%$ (fractions $1,2,9$ ) (Table S1)). Many unique peptides were found in one or two fractions in both experiments (Fig. 2B) in the presence or absence of LMW color pI markers. Thus, this spreading was not due to LMW color pI markers but mainly to isoelectric focusing of a noncomplex sample (see theoretical OGE isoelectric focusing of HSA digest in Fig. S1).

\subsection{LMW color $\mathrm{pI}$ markers do not generate adduct ions}


In order to ensure that LMW color pI markers did not form any adduct ions that may mask specific peptide signals and hence interfere in protein identification, we compared MS spectra of colored fractions $(1,9,13,17$ and 20) obtained after OGE fractionation of HSA with LMW color pI markers and MS spectra obtained from the same OGE fractions of HSA in the absence of LMW color pI markers, (Fig. 3). For markers II, III, IV and V, no additional ions were observed in the presence of LMW color pI markers compared to the ones observed in the absence of LMW color pI markers. This suggests that markers II, III, IV and V did not form any adduct in the mass range of $m / z, 700-3500$. For pI marker I, we observed two supplemental ions in high abundance at $m / z, 1629$ and 2049 when HSA was in combination with LMW color pI markers. The ion at $m / z 1629$ corresponds to a loss of $\mathrm{H}_{2} \mathrm{O}(18 \mathrm{u})$ from the ion at $m / z 1647$. Further investigations could be done to identify exactly the sequence of the ion at $\mathrm{m} / \mathrm{z} 2049$ for the case of in pI marker I. For markers II, III, IV and V, no adducts have been highlighted using our approach.

\section{5 iTRAQ Quantification of HSA with or without LMW color pI markers}

In this section, we evaluated the impact of LMW color pI markers on fractionation of HSA peptides previously labeled with iTRAQ. HSA peptides were unevenly distributed along the strip in both labeled and unlabeled HSA (Fig. 2A and 2C). Most of labeled HSA peptides were found in 1, 2 or 3 successive fractions and were less spread compared to HSA that was unlabeled (Fig. 2D). Moreover, we identified a larger number of peptides in labeled HSA (Table S2). This benefits of iTRAQ labeling on peptide identification is in agreement with other studies $[2,6]$. It was shown that iTRAQ reagents improve MALDI ionization due to the tertiary amines groups of iTRAQ reporter groups that increase the proton affinity of labeled peptides [20].

On the other part, we observed an expected high resolution focusing of LMW color pI markers II and IV in fractions 9 and 17, respectively along the strip. We noted a close focusing shift of pI marker I from fraction 1 to fraction 2, a shift of pI marker III from fraction 13 to fraction 14 and 
a shift of $\mathrm{pI}$ marker $\mathrm{V}$ from fraction 20 to fraction 22 . These $\mathrm{pI}$ shifts were basic $\mathrm{pI}$ shifts in the OGE fractionation process and could be due to iTRAQ reagents, since no shifts were observed when HSA was unlabeled and fractionated with LMWcolor pI markers (part 3.3). As previously

reported [6, 9], a non-negligible basic pI shift has already been observed in OGE fractionation of iTRAQ labeled peptides compared to native peptides using a wide $\mathrm{pH}$-range 3 to 10 while a slight or negligible pI shift was observed using acidic $\mathrm{pH}$ range 3.4 to 4.9 [11].

\section{6 iTRAQ quantification of complex sample such as a human proteome (HP)}

The bioinformatics iTRAQ-based OFFGEL-nanoLC-MALDI-TOF/TOF analyses for the complex Human Proteome (HP) sample resulted in the identification and the quantitation of similar peptide numbers using a local FDR of $1 \%$ for experiments with and without LMW color pI markers. Indeed, we observed a symmetrical shape between both conditions with a slight loss of peptides in the presence of LMW color pI markers (11350 vs 10878, Fig. 4). With regard to the LMW color $\mathrm{pI}$ marker impact on the $\mathrm{pI}$ value, we observed that experimental $\mathrm{pI}$ values were generally similar in both experiments (with or whitout LMW color pI markers) (Fig. S3). Moreover, the calculation of $\mathrm{pI}$ value for each quantified peptide showed that the average experimental $\mathrm{pI}$ value deviated from the theoretical $\mathrm{pI}$ value (calculated according to the IPG strip supplier data) by an average error of $+/-0.5$ in both experiments.

Most of the HP unique peptides were found in a single fraction or were distributed in one or two fractions (Fig. 4B). Those observations are in agreement with the results reported in previous studies based on the fractionation of complex samples $[2,6,20]$. This was observed in the presence or absence of LMW color pI markers. It should be also noted that in the presence of LMW color pI markers, we only observed a slight decrease of identified peptide number. Regarding LMW color pI marker focusing, LMW color pI marker II, III and IV were found at fraction 9, 14 and 17 respectively, as reported with single HSA experiment (Fig. 2C). Moreover, for the LMW color pI markers III and IV, we observed a lower residual color in the previous 
fraction. On the other hand, LMW color pI markers I and V were found in two successive fractions with one fraction shift compared to the HSA experiment. The most rational explanation for this observation is that the fractionation time of $40 \mathrm{~h}$ for the HP experiment to reach $50 \mathrm{kVh}$ for the global voltage accumulation was greater than the $10 \mathrm{~h}$ for the HSA experiment. These results suggested that the compromise between OGE focusing efficiency and OGE focusing time may be optimized by stopping OGE of the HP sample when the LMW color pI markers reach their specific OGE fraction. Indeed, the OGE process requires a long time to complete the fractionation (i.e. usually a few days) especially in the presence of a high concentration of salts [1]. Displaying LMW color pI markers could be a way to decrease OGE separation time by stopping OGE when LMW color pI markers are focused at their specific OGE fraction. We could also use LMW color pI markers at lower concentrations to have the color pI markers in a single OGE fraction. Otherwise, although analysis of nanoHPLC chromatograms of HP peptides in colored OGE fractions led us to identify peaks with a high UV signal corresponding to LMW color pI markers from 20 min retention time (Fig. S2), LMW color pI markers have no impact on column and precolumn pressures during nanoHPLC separation, either for identification or quantification of the peptides.

\section{Concluding remarks}

OGE is a suitable technique to focus a mixture of LMW color pI markers (I to V) as well as individual LMW color pI markers. OGE used in presence of a mixture of LMW color pI markers enables coverage of the entire $\mathrm{pH}$ scale between 3 and 10, so is very useful to follow peptidefocusing. Moreover, this approach is compatible with both identification and iTRAQ quantification of proteins in complex samples. Therefore, the use of the five LMW color pI markers enables control of the OGE focusing of peptides in real time within a large $\mathrm{pH}$ range from 3 to 10. Furthermore, pI marker electrofocusing may help to collect specific fractions at desired $\mathrm{pH}$ ranges. 
I-A

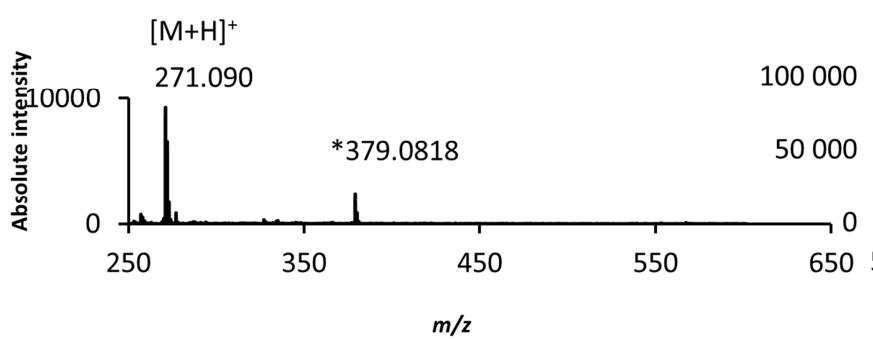

I-B

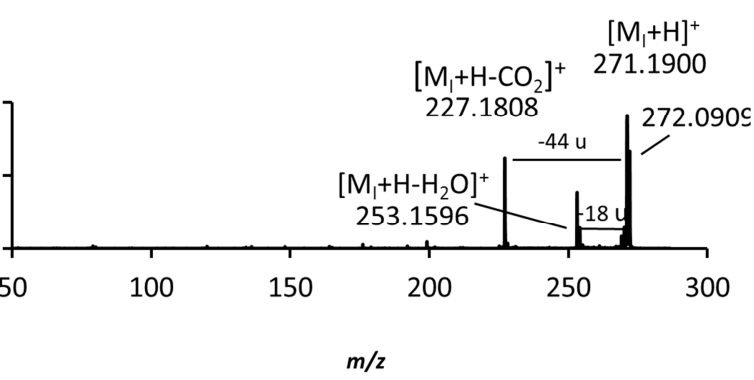

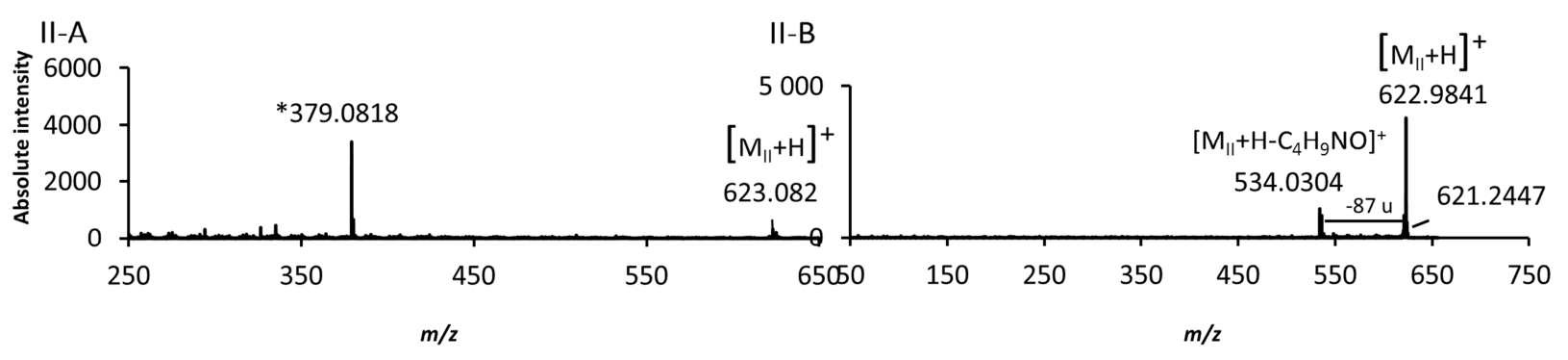

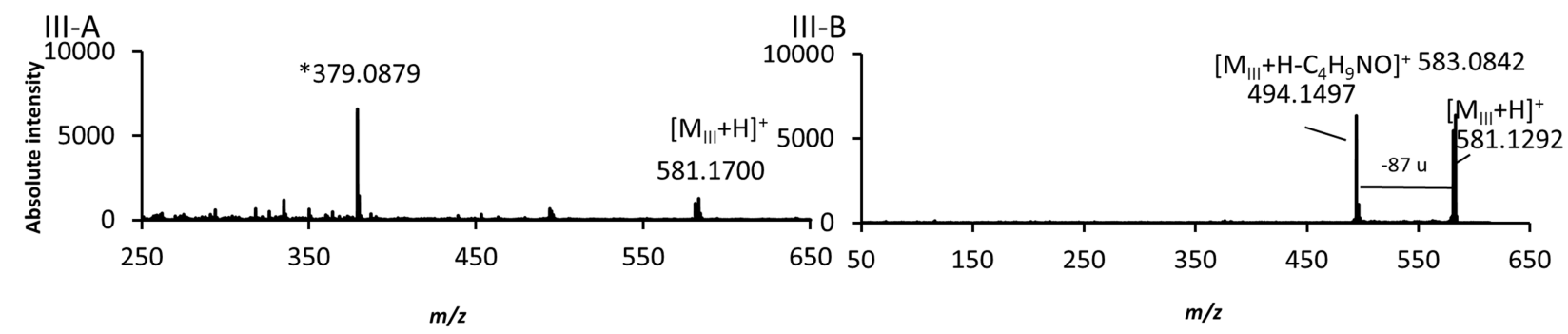

IV-A

IV-B
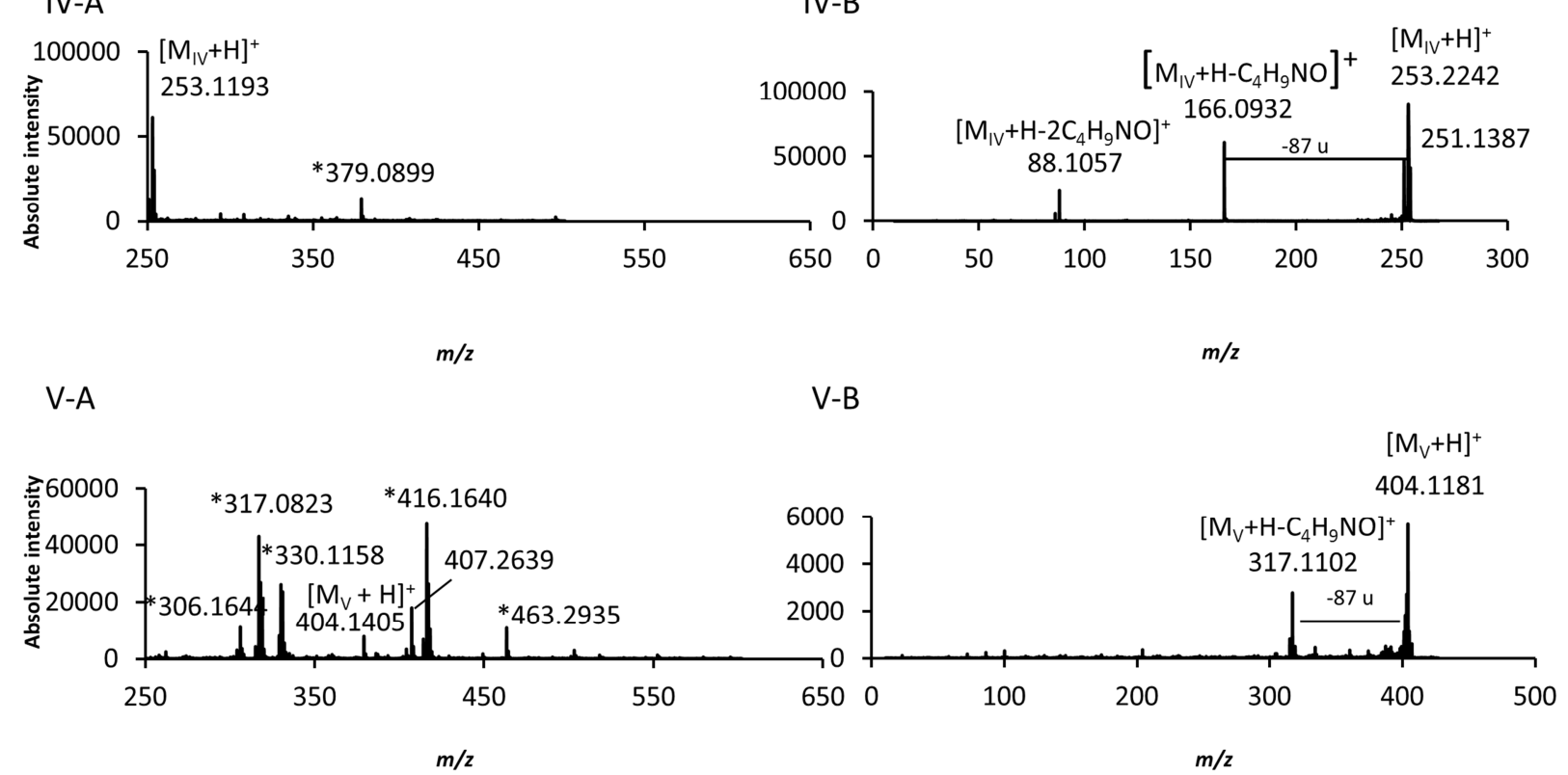

Figure 1 

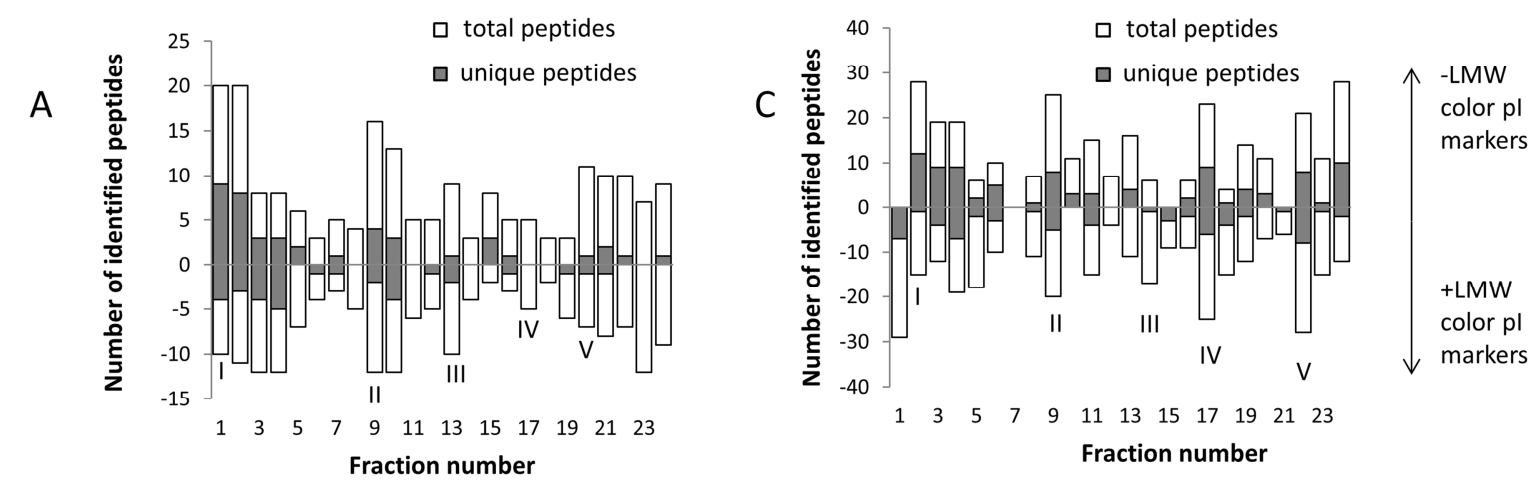

B
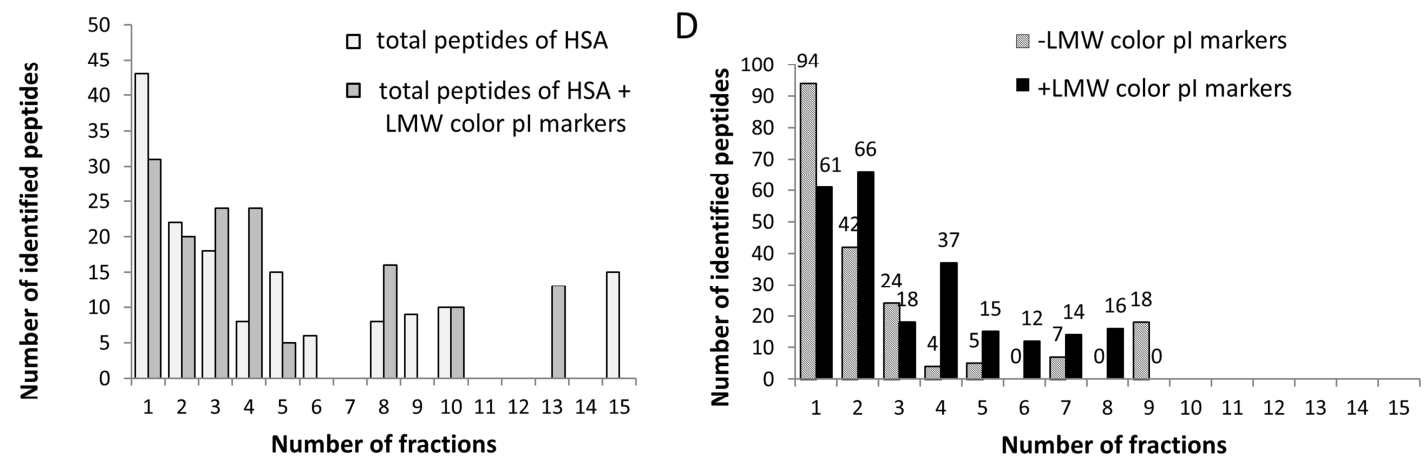

Figure 2 


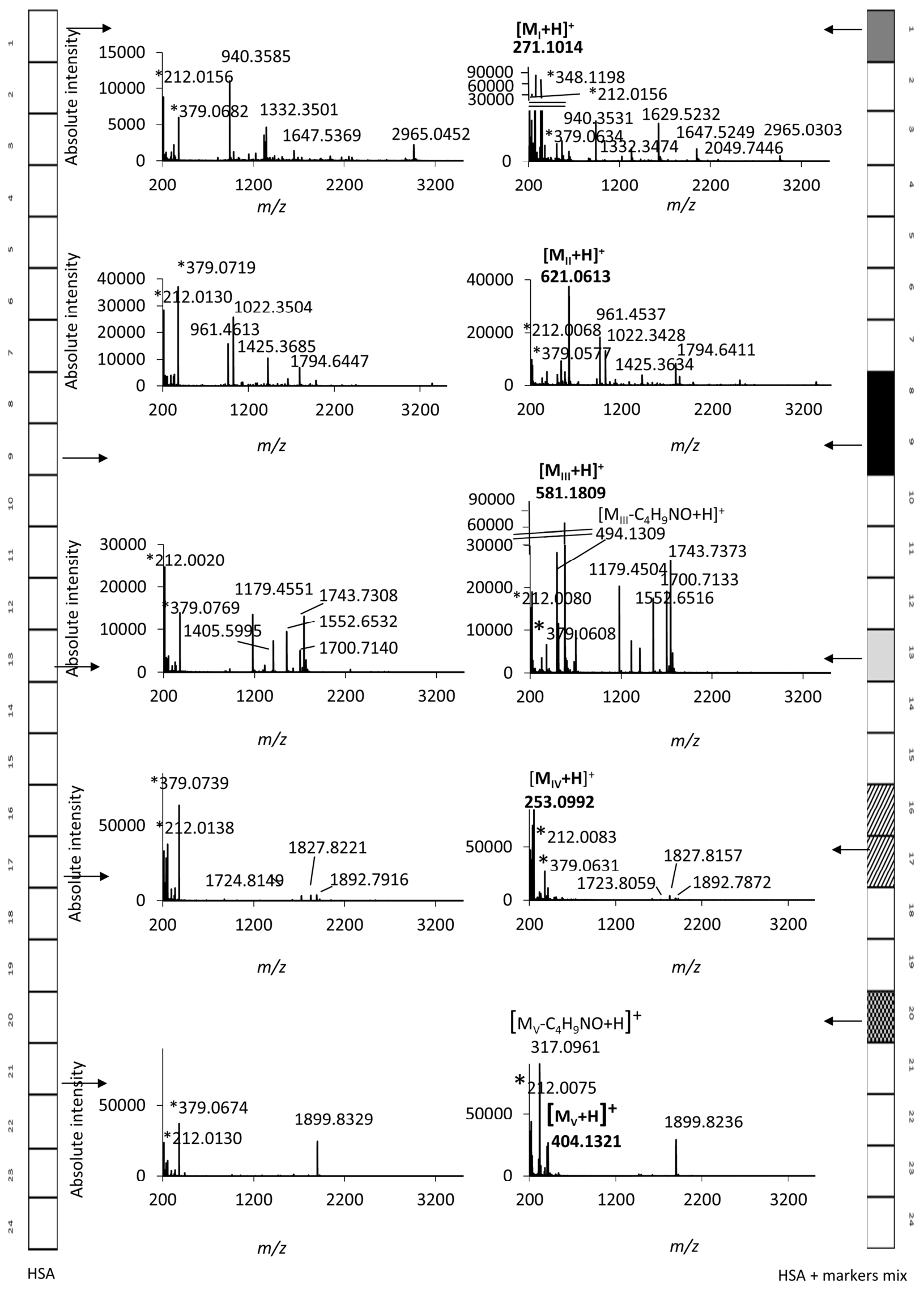

Figure 3 

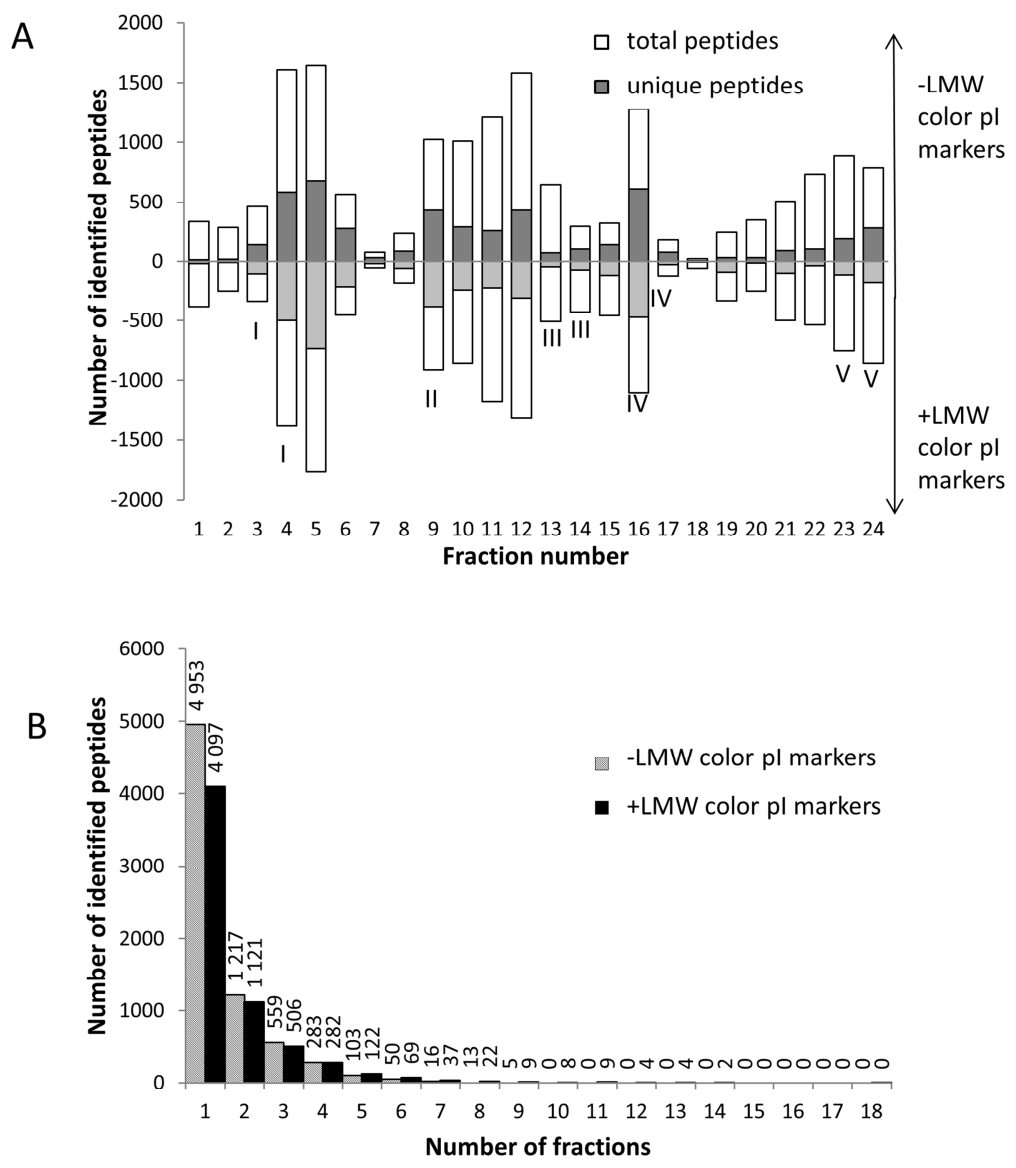

Figure 4 


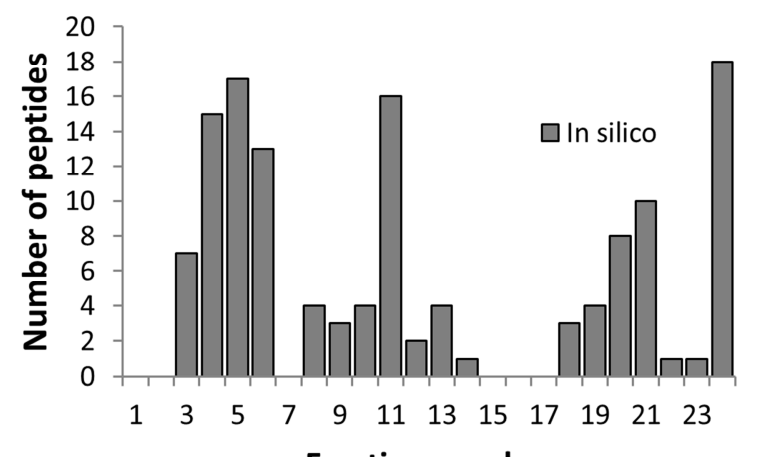

Fraction number

Figure 5 (S1) 

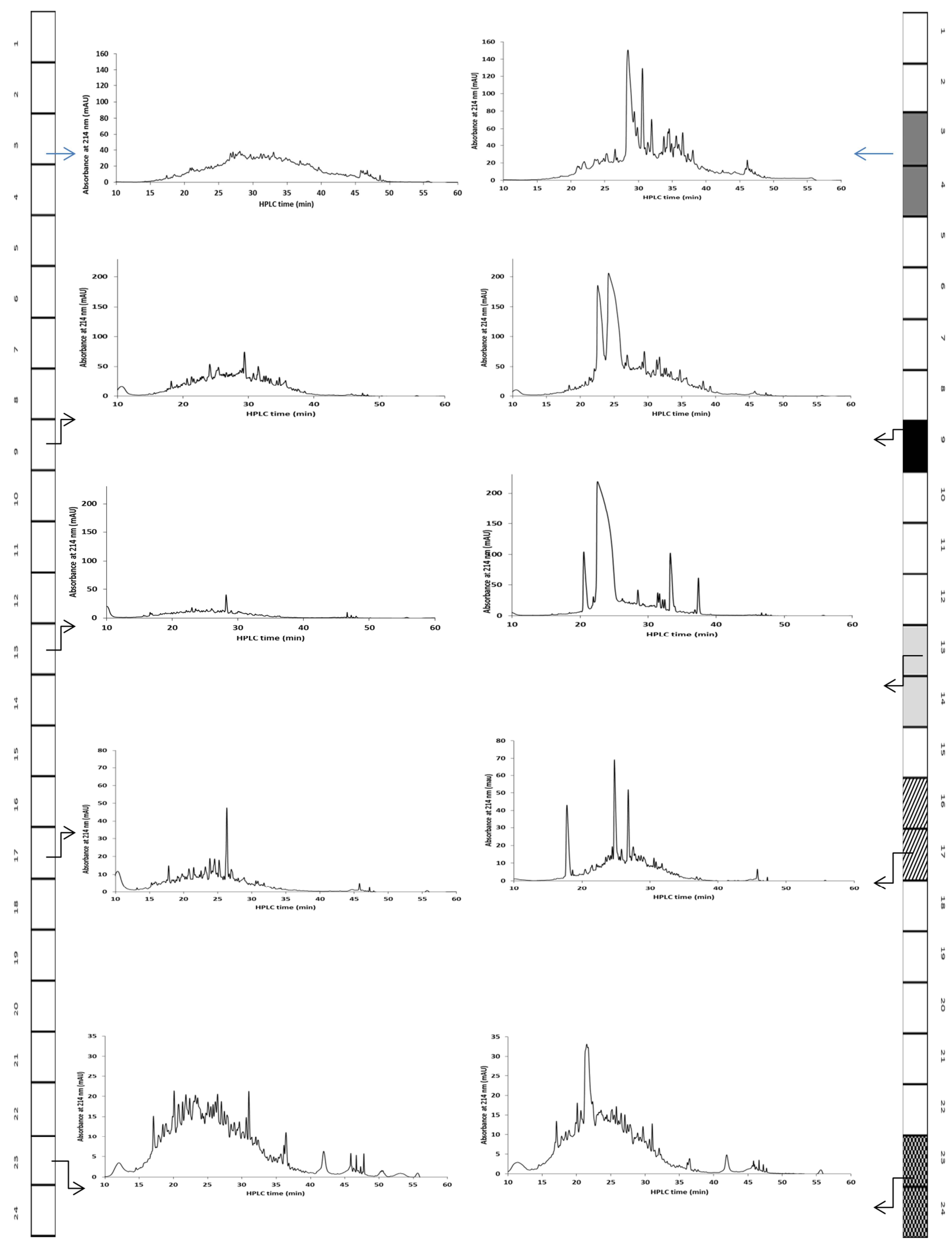

Figure 6 (S2) 
A

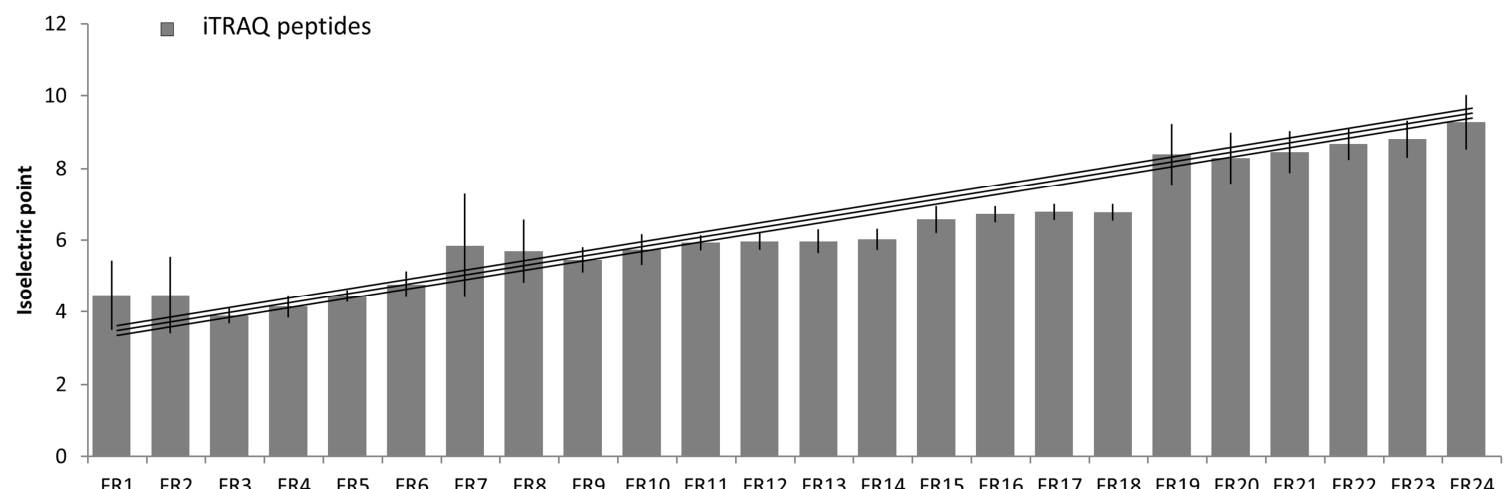

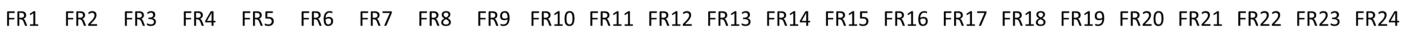

B Fraction number

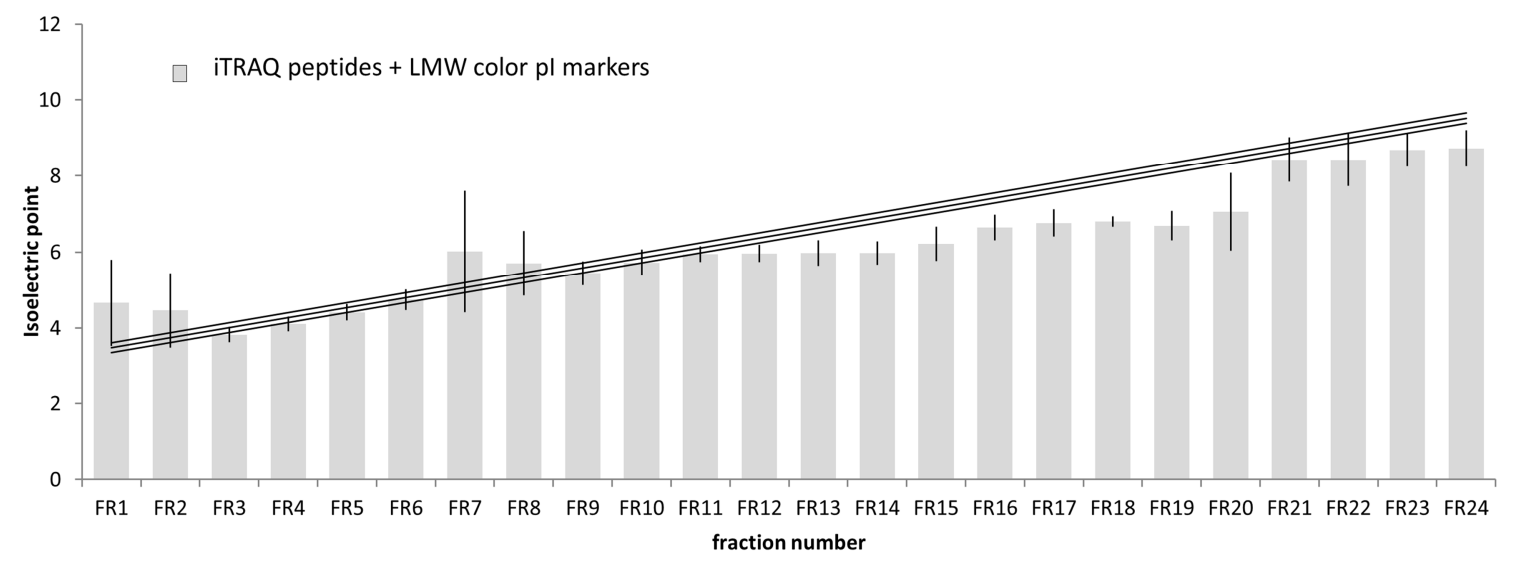

Figure 7 (S3) 


\section{References}

[1] Moreda-Piñeiro, A., García-Otero, N., Bermejo-Barrera, P. Anal. Chim. Acta., 2014, 836, 117.

[2] Hörth, P., Miller, C. A., Preckel, T., Wenz, C. Mol. Cell. Proteomics, 2006, 5, 1968-1974.

[3] Ross, P.L., Huang, Y.L.N., Marchese, J.N., Williamson, B., Parker, K., Hattan, S., Khainosski, N., Pillai, S., Dey, S., Daniels, S., Purkayastha, S., Juhasz, P., Martin, S., BartletJones, M., He, F., Jacobson, A., Pappin, D. J. Mol. Cell. Proteomics. 2004, 3, 1154-1169.

[4] Bakalarski, C.E., Kirkpatrick, D.S. Mol. Cell. Proteomics. 2016, 15, 1489-1497.

[5] Rauniyar, N., Yates, J.R. J. Proteome Res. 2014, 13, 5293-309.

[6] Chenau, J., Michelland, S., Sidibe, J., Seve, M. Proteome Sci. 2008, 6, 9.

[7] Besson, D., Pavageau, A. H, Valo, I., Bourreau, A., Belanger, A., Eymerit-Morin, C., Mouliere, A., Chassevent, A., Boisdron-Celle, M., Morel, A., Solassol, J., Campone, M., Gamelin, E., Barre, B., Coqueret, O., Guette, C. Mol. Cell. Proteomics. 2011, 10, M111 009712.

[8] Lukic, N., Visentin, R., Delhaye, M., Frossard, J. L., Lescuyer, P., Dumonceau, J.M., Farina, A. BBA-Proteins Proteom. 2014, 1844, 1026-1033.

[9] Abdallah, C., Sergeant, K., Guillier, C., Dumas-Gaudot, E., Leclercq, C. C., Renaut, J. Proteome Sci. 2012, 10, 37.

[10] Fukao, Y., Kobayashi, M., Zargar, S.M., Kurata, R., Fukui, R., Mori, I.C., Ogata, Y. Proteomes. 2016, 4, 1.

[11] Lengqvist, J., Uhlen, K., Lehtio, J. Proteomics. 2007, 7, 1746-1752. 
[12]Stastná, M., Trávnícek, M., Slais, K. Electrophoresis. 2005, 26, 53-59.

[13] Duša, F., Šlais, K. Electrophoresis. 2013, 34, 1519-1525.

[14] Slais, K., Friedl, Z. J. Chromatogr. A. 1995, 695, 113-122.

[15] Slais, K., Friedl, Z. J. Chromatogr. A. 1994, 661, 249-256.

[16] Štastná, M., Šlais, K. Anal. Bioanal. Chem. 2005, 382, 65-72.

[17] Michel, P.E., Reymond, F., Arnaud, I.L., Josserand, J., Girault, H.H., Rossier, J.S. Electrophoresis. 2003, 24, 3-11.

[18] Shimura, K., Zhi, W., Matsumoto, H., Kasai, K. Anal. Chem. 2000, 72, 4747-4757.

[19] Mazanec, K., Slais, K., Chmelík, J. J. Mass. Spectrom. 2006, 41, 1570-1577.

[20] Ernoult, E., Gamelin, E., Guette, C. Proteome Sci. 2008, 6, 27.

\section{Figures Captions}

Figure 1. MS (A) and MS/MS (B) spectra of individual LMW color pI markers obtained with HCCA as matrix after OFFGEL electrophoresis. I, II, III, IV and V are the pI marker's number. *ions from matrix HCCA.

Figure 2. Analysis of HSA digest (A) Total number of peptides identified per fraction in HSA sample digest in the presence or absence of LMW color pI markers (143 and 153 respectively), (B) Fractionwise distribution of identified peptides in HSA sample digest, (C) Total number of peptides identified per fraction in HSA sample digest labeled with iTRAQ in the presence or absence of LMW color pI marker mix, (D) Fractionwise distribution of identified peptides in HSA sample digest labeled with iTRAQ. 
Figure 3. MS spectra of HSA digest with (at right) and without (at left) LMW color pI marker mix for OGE fraction showing marker focusing.

Figure 4. Human Proteome digest study (A) Total number of peptides identified and quantified per fraction in HP sample digest in the presence or absence of LMW color pI marker mix. Also reported are the number of individual visible LMW color pI markers. (B) Fractionwise distribution of identified and quantified peptides.

Figure S1. In silico repartition of all peptides identified for HSA protein.

Figure S2. NanoHPLC chromatograms of HP labeled with iTRAQ with or without mix of dyes. Figure S3. Average experimental pI values for all peptides identified by fraction. HP iTRAQ spiked without (A) and with (B) LMW color pI markers. Error bars indicate the standard deviation of each fraction's experimental pI. The middle line is the average of theoretical pI values. The solid lines are based on the theoretical pI values calculated for the IPG strips (pH 310). 
Table 1. LMW color pI markers used for peptides OGE electrofocusing.

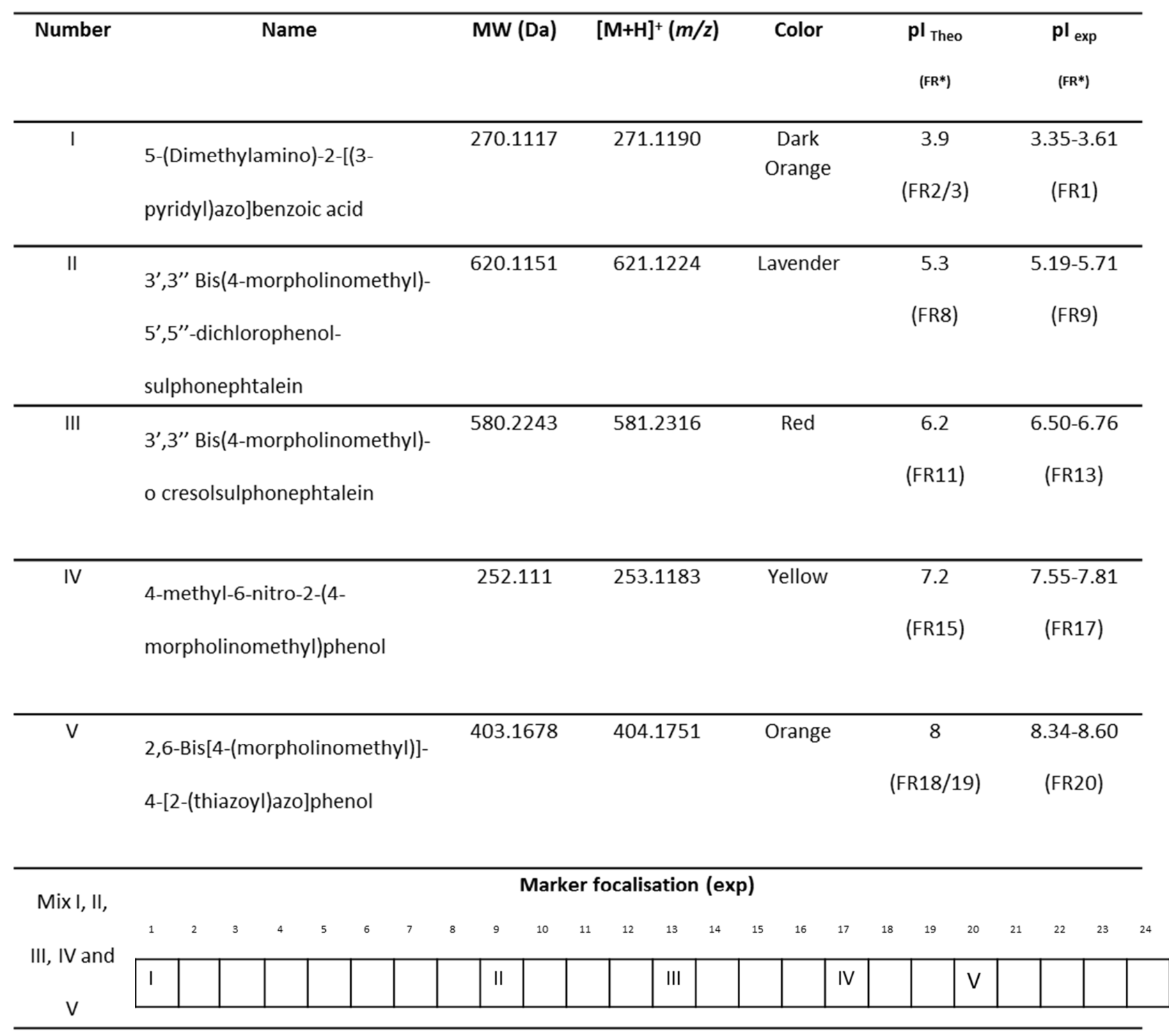

*conditions: 26h/50kVH, 24-cm IPG gel strip linear pH 3-10 